\title{
Agency in dementia care: Systematic review and meta-ethnography.
}

Mr Alessandro Bosco ${ }^{1}$, Professor Justine Schneider ${ }^{2}$, Dr Donna Maria Coleston-Shields ${ }^{1}$, Dr Kaanthan Jawahar ${ }^{1}$, Professor Paul Higgs ${ }^{3}$, Professor Martin Orrell ${ }^{1}$

Affiliation: ${ }^{1}$ Division of Psychiatry and Applied Psychology, School of Medicine, University of Nottingham, Nottingham, United Kingdom; ${ }^{2}$ School of Sociology and Social Policy, University of Nottingham, Nottingham, United Kingdom. ${ }^{3}$ Division of Psychiatry, Faculty of Brain Sciences, University College London, London.

Corresponding author: Mr Alessandro Bosco, Room A10, Institute of Mental Health, Innovation Park, University of Nottingham, Triumph Road, Nottingham NG7 2TU, United Kingdom. Email: Alessandro.bosco@nottingham.ac.uk Phone: (+44) 7453512212. 


\section{Abstract}

Objectives: Dementia often limits the agency of the person to such an extent that there is need for external support in making daily life decisions. This support is usually provided by family members who are sometimes legally empowered to engage in decision making on behalf of the person for whom they care. However, such family carers receive little or no information on how to best provide support when there is a lack of capacity. This may have an impact on the agency of the person with dementia. This review explores the experience of agency in people living with dementia.

Design: A systematic search was conducted on IBSS, MedLine, PsychINFO, EMBASE, and CINAHL. Two independent researchers screened the studies and conducted the quality appraisal. We used meta-ethnography for data analysis. As part of the synthesis, we identified behavioural mechanisms underlying the process of decision making and looked at how the support of carers comes into play in making deliberate choices.

Results: The meta-ethnography involved 20 studies. Three levels of third-order constructs were identified, each describing a decision-making pathway and reflecting the degree of autonomy of the person with dementia: autonomous decision-making, shared decisionmaking, and pseudo decision-making. Findings highlight those inter-relational processes that promote or negatively impact on the agency of people with dementia.

Conclusions: Our review will provide health and social care personnel with an understanding of the role of the carer in the decision-making-process, and therefore which mechanisms need to be promoted or discouraged through training.

Words $246 / 250$

Keywords: Dementia, agency, decision-making, autonomy, metacognition.

Running title: Agency in dementia care 


\section{Introduction}

Dementia can limit the agency of people with dementia, whose decreased ability for risk assessment, makes them more vulnerable to abuse, accidental self-harm, or self-neglect (Hegde and Ellajosyula, 2016). Although dementia is associated with reduced ability to make informed choices, the UK Mental Capacity Act (2005) explains that decision-making capacity is specific to the time when it needs to be taken (situational), rather than as a capacity that the individual either has or lacks (Department of Health, 2005). The United Nations Convention on the Rights of Persons with Disabilities (UN-CRPD) asserts that all persons, irrespective of their disabilities, are entitled to exercise legal capacity and receive adequate support, if needed (UN-CRPD, 2006).

In case the individual is found to lack capacity, family members are faced with the difficult task of supporting them in their decisions or making decision on their behalf when necessary (Mental Capacity Act, 2005). These family members are usually providing direct and intensive care and may, in the UK, hold Lasting Power of Attorney (LPA) for the person with dementia or be appointed as Deputies by the Court of Protection. The role of the family carer then becomes that of balancing their tasks of caring for the person with dementia with the tasks of intervening in complex life decisions (Livingston et al., 2010). This balance may be challenged by the onset of a crisis in the person with dementia, when health professionals turn to family members to make momentous decisions on limited care options (ADI, 2016). This is source of distress for carers and a threat to the agency of their relatives with dementia (ADI, 2016).

In this review, agency in dementia is understood of as the 'ability to initiate social action or at least influence their own personal circumstances' (Boyle, 2014), using a social constructivist standpoint for agency, intended as action acted out by socially-situated individuals through human interaction (Berger and Luckmann, 1991). Social reality is then explained as a product of human inter-relations. This interpretation is further informed by structuration 
approach to explain social change, in how social structures lie within the reflexivity of both individuals and institutions which combine to influence human behaviour without necessitating a deterministic temporal ordering (Giddens, 1986). This means that social structures can influence agency across time, as previous social structures can influence current behaviours and existing structures can affect future human behaviours (Giddens, 1986). It is also important to realise that discussing agency in relation to dementia can be problematic for notions of selfhood, which may necessitate other modes of expression such as personhood (Higgs and Gilleard 2016). This has often presented itself as an 'absent presence' constituting one of the dimensions of the fourth age - ageing without agency (Gilleard and Higgs, 2010).

The aim of this review is to explore how decision-making is expressed by the person with dementia living in the community and promoted by their carers.

\section{Methods}

The study complied with the PRISMA checklist (Moher et al., 2009).

Hierarchical modelling for decision making. Decision making and agency require a degree of cognition to influence social change, and for this reason, the five-level hierarchical cognitive model, proposed by Lonergan (2000), may be used to explain the process of agency (see appendix A1 published as supplementary material online attached to the electronic version of this paper at https://www.cambridge.org/core/journals/internationalpsychogeriatrics).

In the model, the first four levels represent the 'insight' of the individual, a conscious process requiring the awareness of each of the ascending levels (Lonergan, 2000). Individuals first attend to the data through the senses or feelings, then data are experienced through cognition and an understanding is then attained. When individuals understand the experience (i.e. data), they form a judgment of it; a self-oriented process that answers the question 'is this correct'? Finally, they are ready to make a decision (Lonergan, 2000). 
The process may also be recursive when new questions arise during the process, either selforiented, or posed by the event. We used the cognitive model by Lonergan (2000), as a meta-model to inform the translation process of the meta-ethnography.

Identification of qualitative data. The Patient Intervention Comparison Outcome (PICO) format identified the population and outcomes of our search strategy (Sackett et al., 1997), conducted on 15.02.2018 on five databases: IBSS, MedLine, PsychINFO, EMBASE, and CINAHL. The Medical Subject Headings (MeSH) terms ('decision-making', 'shared decisionmaking', or 'patient decision-making') were added to the search and combined with the terms 'dementia' and 'Alzheimer's'. We further cross-referenced articles and conducted an explorative search of the first 100 hits on Google Scholar and Google search engine.

The lead author $(A B)$ developed the search strategy, which was checked for accuracy by an experienced librarian (EY). Two rounds of process plan were necessary. A three-stage process was followed for the screening and selection of relevant sources: Firstly, the qualitative researcher $(A B)$ and a Specialty Registrar in Psychiatry (KJ) independently ran preliminary title and abstract screening against the inclusion/exclusion criteria; secondly, $A B$ screened the full text of the remaining articles. A final stage involved the independent appraisal of the selected articles.

Inclusion criteria for the selection of studies. Qualitative empirical studies were considered when their primary objective was one or more of the following: Agency, decision making, active participation in health care delivery (e.g. care plan) or activities of daily living (ADLs).

\section{Inclusion criteria:}

- Used qualitative methods and reported first order constructs (quotations from participants).

- Key word dementia or Alzheimer's. 
- Published from 2005 onwards.

- Reported on the experience of agency in people with dementia living in their own homes. Multiple perspectives may be present, (e.g. how agency is experienced by family carers or promoted by health care professionals).

\section{Exclusion criteria:}

- Concerned palliative care or decision making during end-of-life care.

- Commentaries, clinical discussions around case studies with no reported quotations from participants.

The role of the expert team. The expert team comprised three professionals with expertise in old age psychiatry (MO), social care in dementia (JS) and neuropsychology of old age (DMCS). They advised on strategies for the retrieval of articles and contributed to the synthesis of the findings.

\section{Data analysis}

The quality appraisal of the studies was conducted by two researchers independently $(A B$ and $\mathrm{KJ}$ ), through the Critical Appraisal Skills Programme (CASP) checklist for qualitative research.

Inter-rater agreement was assessed with the Kappa coefficient (Cohen's Kappa) (Cohen, 1960). Discrepancies were addressed through consensus. The parameters were based on the ranges by Landis and Koch (Landis \& Koch, 1977): $0.81-1.00=$ almost perfect; $0.61-$ $0.80=$ substantial; $0.41-0.60=$ moderate $; 0.21-0.40=$ fair $; 0.00-0.20=$ slight $;<0.00=$ poor.

Meta-ethnography. Noblit and Hare's (1988) approach was used for analysis. We used Schultz's (1962) categorisation of first-order constructs (participants' quotations) and second-order constructs (authors' interpretation of participants' quotations) to derive our third-order constructs on which we base our interpretation of the review results. We also 
followed the principles of 'reciprocal translation' by Noblit and Hare (1988) to analyse the emerging themes as they were presented in each of the studies included in the review. In addition, we developed a linear model to graphically represent the translation process of our third-order constructs. A line of argument further explained our analytical interpretation of data synthesis and was reported graphically and explained by means of a self-regulating model in decision making, which was informed by the organisational model by Jones (1997). In regard to the identification of concepts/themes, our approach was iterative, in that we read and re-read the studies included in the review, with a focus on the first-order constructs (reported in the analysis/results section) and the second-order constructs of the studies (reported in the results and discussion sections). This analytical process entailed the qualitative researcher $(A B)$ extracting the first- and second-order constructs by text units (i.e. paragraphs) onto NVivo 11 (QSR International, 2012) for the re-organisation of the layers of interpretations. For this purpose, the use of NVivo helped create a conceptual map for theme development in the form of a table, in which each column mapped themes against first- and second-order interpretations.

Initial themes were found around the degree of involvement of the person with dementia and their carers in decision making with respect to ADLs, and advanced care planning at different stages of the condition; themes were also found around the behaviours of the carer and the person with dementia to promote and retain autonomy, and the active involvement of health professionals in providing support for making health care decisions.

A discussion was held with the expert team to check for accuracy. Lonergan's hierarchical model was employed to organise themes according to the mechanisms relating to different decision-making pathways. For this purpose, theme categories around what promotes or prevents autonomous decisions informed our third-order construct 'autonomous decisionmaking pathway'. The role of the carer in shared decision making and the strategies employed to make consensual decisions constituted the third-order construct 'shared decision-making pathway'. Themes relating to false or staged decision making and 
contributing factors guided the synthesis of the third order construct 'pseudo-decisionmaking pathway'.

\section{Results}

The search retrieved 6,447 studies (IBSS: 730; CINHAL: 519; PsychINFO: 776; Ovid MEDLINE: 2055; EMBASE: 2367). Fifty-three articles were matched against our inclusion/exclusion criteria; 33 were excluded with reasons (e.g. on palliative care, studies on nursing homes) and 20 were analysed through meta-ethnography (Figure 1).

Study characteristics. The included studies were published in peer-reviewed journals between 2005 and 2017, five studies employed mixed methods design and the remaining 15 used qualitative methods only for data collection and analysis (Table 1). The studies could be grouped into six broad categories around decision making: Every day decision making $(n=9)$, proxy decision making $(n=4)$, Advanced Care Planning $(n=3)$, gender categorisation in decision making $(n=2)$, driving cessation $(n=1)$, and financial management $(n=1)$.

Quality appraisal. All studies were found of moderately high quality (range $0.63-0.87$ ). It was relatively difficult to assess articles on the clarity of methods used for data collection and on the appropriateness of recruitment strategy, as the authors rarely reported on these aspects.

Meta-ethnography. Three third-order concepts emerged from the analysis, each reflecting a different pathway of decision making according to the degree of autonomy in the person with dementia: autonomous decision making, shared decision making, and pseudo-autonomous decision making. Each third order construct comprised theme categories as shown in Table 2. The conceptual map on decision making was reported in Figure 2.

Although autonomous decisions could be made during any stages of the condition, it appeared that they were more likely to occur in early stages of dementia (Hirschman and Xie, 2004). Judging by the evidence gathered, people with moderate dementia are more 
likely to require a substantial support from their carers and to express their wishes and preferences through shared decision making. In advanced stages of dementia, when symptoms restricted the expression of agency, decisions tended to be made on behalf of the person, and this appeared to take place through pseudo decision making (Hirschman and Xie, 2004).

Following Lonergan's (2000) cognitive model, metacognition emerged as an enabler for people with dementia to practise their agency autonomously. Metacognition is a selfcharacterising process and comprising processes of self-awareness, self-monitoring, and making judgment with respect to a situation (Prinsloo and Barrett, 2017). Hence, metacognitive processes are predictors of capability (Prinsloo and Barrett, 2017).

\section{Autonomous decision-making pathway}

Autonomy is dependent on the preserved cognitive abilities in the person with dementia to effectively understand the situation and make a judgement over possible decisions, and on the strategies put in place to moderate the symptoms of dementia. The degree of assertion of autonomy in the person with dementia when making decisions, proves also key in determining their ability to express an autonomous response.

Preserved cognitive ability. During the early stages of dementia, having their cognitive abilities acknowledged helps contain the negative effects of cognitive decline and increase the opportunities to participate in deliberate decisions. The carer can help retain a positive view towards the selfhood of the person with dementia and extends opportunities for them to initiate social action:

'... She still does pay most of the bills...just said to her...'I haven't paid the water bill' and she says, 'oh, I've paid it'. (Family carer, p.557, Boyle, 2013a)

Acknowledging people with dementia as active agents can lead carers to negotiate between the actual ability of the person they care for and what is best to do to promote a sense of 
autonomy. This is especially found in decision making around activities promoting a sense of identity:

'I've thought about it [stopping driving] ... He's already unhappy to lose a job.... And now for him on top of that to not being able to drive - it's not good.' (Family carer, p.51, Adler, 2010)

The act of acknowledgement is not only external to the individual and promoted by others, but it is also self-directed. When people with dementia maintain positive views around their 'ability of being', they are more likely to engage in social action. Self-awareness with respect to cognitive impairment is associated with the ability to effectively engage in autonomous decision making. As such, the person is able to experience the context by consciously assessing the risk before making a final decision: 'I still drive, although, by the way, I wouldn't drive today!' (Person with dementia, p.147, Fetherstonhaugh et al., 2013).

A powerful sense of one's autonomy may struggle against awareness of the dementia diagnosis when a person considers their own capacity for self-determination:

'...I'm in complete control of my own, whatever I want, intend to do... So I don't have any sense of being lost control of my actions or my thoughts... if that's what you do if you've got Alzheimer's... What is [sic] the traits of Alzheimer's?' (Person with dementia, p.437, Macquarrie, 2005)

Strategies to promote autonomous decisions. Autonomous decisions seem to rely on certain support strategies that are either self-enacted (i.e. by the person with dementia) or carer-enacted. These strategies target the metacognitive regulation process to effectively orientate, monitor, and test the response to the event (Brand-Gruwel et al., 2009).

People with dementia make use of aids to enact their agency and to mediate their cognitive decline. Self-enacted strategies also increase a sense of independence (Fetherstonhaugh et al., 2013). A person with dementia used a daily diary and monitoring, and testing processes were key for her to make plans: 
'It jogs the memory all the time. 'Oh I remember we had that heavy rain', and 'The cleaning lady came'. If I didn't have this little book, I'd be lost.' (Person with dementia, p.147, Fetherstonhaugh et al., 2013)

The use of technology can also be crucial to orientate oneself in regard to the situation. Likewise, carer-enacted strategies aim to instil a sense of autonomy in the person with dementia. For example, in order to maintain independence in the person with dementia, a carer decided to 'make a point of riding with him at least once a week just, you know, for my own benefit of making sure that he's still in command of the vehicle.' (Family carer, p.51, Adler, 2010)

Collaboration between the carer and the person with dementia seems to be key to maintaining agency. The collaboration should ideally aim at supporting the person without directing them, and at making shared decisions. A common adaptive strategy among carers, is to decrease the number of choices, and limit the decision only to the most important matters.

As explained by some authors, in certain cases people with dementia are still able to convey their wishes despite lacking capacity at the time the decision needs to be taken. This occurs through formal directives prepared in advance to represent the will of the person in anticipation of cognitive decline and consequent loss of mental capacity, known as advanced care planning.

As part of their advanced care planning, people with dementia are often required to express their preferences around residential accommodation well ahead of time. Exploring alternatives for future care can confront a person with the real challenges that dementia poses on their life:

'I have no thoughts of going into care but... I know that there's every possibility like other people I could have to go into care and I think about it'. (Person with dementia, p.2017, Dickinson et al., 2013) 
Restricted autonomy by the carer. At times the challenges posed by dementia impact on the overall quality of making deliberate decisions. Bantry et al. (2014) explain that carers may feel the need to prioritise the safety of the person they care for, even if this means restricting their freedom of choice and right for privacy. The authors report the use of GPS to locate their loved ones as a common tracking aid, even if its use was not previously discussed with the person:

'If she knew it was in there there's a possibility she would take it out because she wouldn't know what it was' (Family carer, p.227, Bantry et al., 2014).

These behaviours on the part of the carers may impact on the autonomy of the person with dementia and lead to pseudo decision making (Berry et al., 2015), whereby all decisions are effectively made by the carer and passively experienced by the person with dementia.

However, Macquarrie (2005) explains that there are strategies employed by the person with dementia to avoid being objectified and retain power for decision making. These include expressing an assertion of autonomy:

'I stand up for myself more. Like when (spouse) says something about "We'll do it another time. We don't need them right now." Well I mean I might just say, "Well, I'm going out for a walk." And l'd end up down at the store buying what I want anyway.' (Person with dementia, p.433, Macquarrie, 2005)

As explained by a person with dementia, asserting own independence: 'keeps my independence. It makes me independent. Rather than have somebody say, 'Well we will pick them up next week.'That annoys me. Cause if I want them, I want them now.' (Person with dementia, p.433, Macquarrie, 2005)

\section{Shared decision-making pathway}


This third-order construct describes the instances when the person, because of the symptoms of dementia, needs some external support to fully express agency. A sense of autonomy may still be promoted through shared decision making; however, the degree of involvement of people with dementia depends on the amount of control they relinquish, on whether strategies are employed to sustain their independence, and on the presence of factors that may prevent them from making deliberate choices.

Shared responsibility. Being supported in practising agency requires people with dementia to accept the perspective of the carer in regard to the situation and to relinquish some of their decision power. This perspective-taking process becomes key to retaining agency when the person's ability for self-regulation is affected by dementia:

'I probably take more advice than I used to. I used to be quite bombastic about it: 'No, we'll put up number 2 and that's it!' Now, it's: 'Well I think number 2, what do you reckon lads?' (Person with dementia, p.148, Fetherstonhaugh et al., 2013)

Shared views are key to finalising social actions. Consensus may be reached by both agents, and its importance may influence the cognitive appraisal of the situation:

'Well, we discuss it for a start and see what each one would say and then decide to come to a decision' (Person with dementia, p.7, Harrison Dening et al., 2016)

Samsi and Manthorpe (2013) suggested that to preserve autonomy in the process of making choices, consensus is to be reached by acknowledging each other's needs. This can be achieved through knowing the person for a long time (e.g. being married for many years) or through employing an altruistic stance in the relationship, whereby some of the wish for control is released:

'... I like being at home. We [wife and him] ...decide what we're going to do all day...but if she has one of her Ramblers' (organized walking in countryside) outings, I don't stop her.' (Person with dementia, p.955, Samsi and Manthorpe, 2013) 
Strategies for shared decision making. Just as in autonomous decision making, certain strategies can be identified in the process of making shared decisions. Carers have a key role in supporting the autonomy of the person with dementia. They may, for instance, offer encouragement to engage in tasks requiring a level of perception and understanding of the situation that is adequate to their capabilities.

When the situation requires skills that do not match with the cognitive ability of the person, a strategy to support autonomy is to break down the process of decision making into a series of steps.

To support the cognitive performance of the person with dementia, a further strategy deployed by formal and informal carers is to create structured contexts, whereby the practice of agency becomes function of previous knowledge and negotiations. For instance:

'It is Friday today and on Fridays we have an agreement about showering. Look at your plan for the week written on your board. Come let me help you!' (Community nurse, p.12, Smebye et al., 2012)

At times, decisions are taken out of the hands of the person with dementia, and carers may turn to health professionals to defray the damage that this could cause to their relationship with the individual with dementia. A husband of a driver with dementia felt: 'I think it's better for the doctors to do it, you know, to tell her not to drive anymore.' (Family carer, p.54, Adler, 2010)

This is decision making shared between the carer and the professional, but the involvement of the person with dementia is absent and assumptions are made about her wishes.

Barriers to shared decision making. A person's autonomy can be threatened in instances when the carer or the health professional impose their views, when the person with dementia feels objectified, or when there is a mismatch between the actual capabilities of the person with dementia and what others think the person is able to do. These factors, if not addressed, may lead to pseudo-decision making. 
The role of professionals can negatively impact on the relationship between a person with dementia and the family carer. This has been reported when the support of the professional does not match with the awareness that the person with dementia has of the situation, for instance:

'[O]ur primary physician ... said to my husband I don't think you should continue to drive.... And he [driver] was mad at me after the visit because I am the one who told the doctor he [driver] shouldn't drive.' (Family carer, p.54, Adler, 2010)

Dementia symptoms may affect the structuring cognitive process of people delivering care and lead to biases. This affection is reported in the ability of carers to discriminate between tasks that the person with dementia is able to undertake and leads to generalisations around their ability to promote social change (Boyle, 2013b). These beliefs may lead carers to being more controlling and people with dementia to feeling objectified:

'Annoying thing is she keeps me under observation. Probably a lot to do with household survival.' (Person with dementia, p.432, Macquarrie, 2005)

When the factors that prevent shared decision making outweigh the opportunities for this, then individuals with dementia may be subjected to pseudo-autonomous decision making.

\section{Pseudo-autonomous decision-making pathway}

In pseudo-autonomous processes of decision making the carer takes full responsibility to make decisions on behalf of the person with dementia. As explained by Smebye, Kirkevold, and Engedal (2012), through this process, the preferences, views and needs of the person with dementia are only indirectly considered, and decisions are 'implicit rather than explicit'. This decision-making pathway represents instances of missed opportunity for social action, when maintaining factors promote the lack of autonomous decisions.

Missed opportunity for autonomous decision. Receiving a diagnosis of dementia is often associated with decreased agency in people with dementia, as they are offered less and less 
opportunities for social action. Having fewer opportunities affects the decisional power of the person with dementia, who may become a passive recipient of the carer's will. This may be especially relevant in cases where power imbalance already occurred in the relationship before diagnosis.

Pseudo-autonomous decisions are made also when people with dementia are still able to practise their agency, but because of their decreased cognitive abilities, it would take time for them to express themselves and for this reason, carers perform agency on their behalf:

'...She's rather slow at describing what I can do in six words. I then let the doctor take over but I'm the one who goes in and says 'right, she's having difficulty with her knee...' (Family carer, p.233, Boyle, 2013b)

Gaining more decisional power in the presence of cognitive impairment creates a power imbalance within the care dyad, whereby the carer can become a depository of agency:

'But I mean he would come and say 'anything I can do?' I mean he'd come in the kitchen ....and I say, 'well, I've done it now, thank you', you know.' (Family carer, p.342, Boyle, 2014b)

Some authors report cases when the person with dementia opts out of some social action when aware of their progressive cognitive decline:

'I think gradually ... I have, um ... opted out of major decision-making ... I'm not taking as much responsibility for our lives...It seems to be the natural thing ... As though it's evolved ...' (Person with dementia, p.7, Harrison Dening et al., 2016)

There were examples of choice being restricted by organisational policies, communicated by professionals, with the effect of disempowering the person with dementia and even causing distress: 
'We had a meeting with the social worker and he stated that if we did not want to place her, she had to go two times per week at the day hospital for activities. It was chaos because we had to go there in the morning to get her ready.' (Family carer, p.287, Couture et al., 2012)

Protective factors. The outcome of pseudo decision making may be positive when choices are made in concert with the views and preferences of the person with dementia. A sense of reciprocity, has been reported as a function of quality in decision taken on behalf of the person (Boyle, 2013b). In addition, when agency is ascertained through a range of modes of communication (e.g. through smile to indicate preference), there is increased likelihood of reaching adequate levels of information to ensure that the wishes and needs of the person with dementia are met:

'Yeah, l'd ask her and she'd say, she wouldn't really answer 'yes' or 'no', but she might smile or something like that.' (Family carer, p.233, Boyle, 2013b)

Pseudo decision making is mainly reported in advanced dementia or at times of mental health crises, when a lack of capacity shifts responsibility for making decisions from the person with dementia to the carer or the health professional. Couture Ducharme, and Lamontagne (2012) present the role of health care staff as 'guarantors of quality' for such care decisions, especially at times when the carer becomes disorientated by the variety of choices being explored:

'I talked to the social worker because they didn't know whether or not she would be institutionalized since she was very confused. They said they don't want to remove elderly persons from their current environment because a change in living environment makes them deteriorate faster.' (Family carer, p.287, Couture et al., 2012)

Maintaining factors. It is important to report that there are maintenance factors to pseudo autonomous decision making, which are mainly found in instances when there is inadequate communication between the person with dementia and the carer about the choice to make or when there is a false belief held by the carer over the wishes of the person with dementia. 
Smebye et al. (2012) highlighted how in the presence of important health care decisions that may impact on the life of the carers, choices tend to respond to the carers' needs, rather than those of the person with dementia. For instance, when inquired about the change of residential accommodation from home to nursing care setting for the person with dementia, a carer responded: 'I'm not quite ready for that yet! ... I always need something to do. If not, time passes by so slowly.' (Family carer, p.6, Smebye et al., 2012)

\section{Discussion}

This review explored how intrapersonal and interpersonal factors impinge on the quality of making autonomous decisions.

Line of argument. Through meta-ethnography we found three different pathways, each influenced by the degree of autonomy of the person with dementia: autonomous decisionmaking pathway, shared decision-making pathway and pseudo autonomous decisionmaking pathway. The ability of the person to engage in either pathway is time-bound, hence influenced by the stage of dementia and the physical/behavioural symptoms experienced (e.g. episodes of crises). In addition, we found that the agency of people with dementia is a function of the quality of care they receive and is mediated by the level of ability of the person to engage in metacognitive processes of self-awareness, monitoring and regulation. These metacognitive processes are essential for the quality of assertion of autonomy practised by the person with dementia, as poor self-awareness with respect to the situation but high assertive response for autonomy may lead to risky and poorly judged decisions.

When the organisational model by Jones (1997) is applied to our findings (Figure 3), the negotiation around autonomy between the agents in care is explained as an inverted pendulum that shifts from a structured controlled environment (on the left side of the model) to a complete unstructured environment (right side of the model). An optimal point is reached when the autonomy of the person with dementia is promoted through adequate support and when people with dementia are aware of what they are able to do. This process of self- 
awareness enables the person to self-regulate with respect to the situation, to practice an adequate level of assertion of autonomy, and to ask for adequate levels of support. The less the ability to engage in the meta-cognitive process of self-regulation the less the likelihood to retain autonomy and make positive deliberate choices.

Tripartite negotiations in complex social contexts. Our findings also evidenced that there is constant negotiation between the agents in care (i.e. the person with dementia, the carer, and the health or social care professional). In concert with information systems research and cognitive system theories (Gimpel, 2008; Kristensen and Gärling, 1997), we found that tripartite negotiations differ in degree and require different distribution of powers among the agents. Each agent's position in negotiations depends on the degree of autonomy exercised by the person with dementia.

It follows that, in autonomous decision making, little or no negotiation is needed, as the person with dementia is able to practise agency with little support. The power retained by the person with dementia exceeds the control that others assert over him or her. Metacognitive processes help factor in the changes occurring as a consequence of dementia and assist the person to monitor and regulate themselves in regard to the decision to be made. Chaos is avoided when there is self-awareness. However, the more complex the situation requiring a decision, the more complex the metacognitive processes involved.

In shared decision making, the degree of negotiation is higher and requires a shift of power in favour of the carer. Entropy is avoided when both the carer and the person with dementia adapt dynamically to the situation and when agreement is reached. Here a perspectivetaking process needs to be fostered in which both agents in care self-regulate their own responses with respect to the situation and consider each other's perspective. Shared decision making is characterised by a constant search for balance to deal with the complex decision in hand. 
In pseudo decision making, the person with dementia retains little or no power to negotiate and the professional and family carer effectively become decision makers by proxy. Pseudo decision making occurs in structured and complex care contexts where mental capacity is lacking. Entropy is avoided when decisions find common ground between the parties concerned and reflect the wishes and needs of the person with dementia. This can sometimes be encouraged through attending to non-verbal modes of communication.

Time ordering and fourth age in dementia care. Decision making in dementia gains a time-ordering effect, as the extent to which the person engages in autonomous decisions is bound to the stage of the condition and episodes of crises. This time-ordering effect has favoured the development of the social discourses around the fourth age (Higgs and Gilleard, 2015) and the linked associations of old age, dementia, lack of volition and autonomy. We believe that such social imagery construed around the new contextualisation of ageing, highly impacts on the degree to which agency is practised by people approaching later stages of life. The social imaginary of the fourth age, denotes the unknown nature of old age and it is in contraposition with the cultural dynamics of the third age characterised by 'personal fulfilment and autonomy' (Gilleard and Higgs, 2010). This significantly affects the way agency in dementia is promoted at different levels of society (i.e. within the community and in social and health policy).

Strengths and limitations. This review is the first to explore the impact of metacognitive processes on the practice of autonomy in the person with dementia, and how the role of carers and health professionals influences the outcomes of decision making through negotiation. Its strengths include the use of a powerful search strategy and in the systematic screening of articles conducted independently by two researchers. In addition, the quality of the findings of the meta-ethnography was checked by three experts in dementia care and old age psychiatry.

Limitations are acknowledged in the use of the CASP checklist for qualitative studies, as its methods-oriented approach to screening may not be appropriate for studies employing 
different epistemological paradigms. A possible limitation is the use of 'negotiation' as concept to describe the interaction between the participants, as this term denotes a dynamic exchange occurring in complex care contexts. This assumes a relatively equal distribution of power, but the actual trend is a decrease of power of the person with dementia as the disease progresses.

Conclusions. Our analysis helps increase the understanding of the role of the carer in the decision-making process. It identifies strategies that may help to prevent the disempowerment of people with dementia and to promote their autonomy. It also highlights potentially-detrimental tendencies that can operate and mechanisms, as reported in Figure 2 that may act as promoters and barriers to autonomy in decision making. These mechanisms, positive and less, could potentially be addressed through training (e.g. assertiveness courses to deal with restrictive and controlling environments). It may also be possible to take account of this tripartite formulation of decision pathways in the implementation of the Mental Capacity Act, for example, or in the implementation of advanced directives.

\section{Conflict of interest declaration:}

None

\section{Description of authors' roles:}

All the authors actively contributed to the planning, development and editing of the systematic review. $A B$ designed the review methodology with respect to the search strategy, data analysis, conducted the quality appraisal, data analysis, wrote and edited the manuscript. JS supervised the development of the search strategy, commented on the use of meta-ethnography, contributed to the analysis of findings and edited the manuscript. DMCS supervised the search strategy, checked the accuracy of third order constructs arising form the meta-ethnography, edited the 
manuscript. KJ screened the articles, undertook the quality appraisal of selected studies and edited the manuscript. PH checked the analysis, commented and supervised the editing of the manuscript. MO supervised the whole process of review design for the screening of articles, supervised the analysis process for the metaethnography and edited the manuscript.

Acknowledgments: This work was supported by the Economic and Social Research Council [grant number ES/J500100/1]. The search strategy for the review paper was supported by the Nottinghamshire Healthcare NHS Foundation Trust. 


\section{References}

Alzheimer's Disease International (ADI). (2016). World Alzheimer Report 2016: Improving healthcare for people living with dementia, coverage, quality and costs now and in the future. Alzheimer's Disease International (ADI): London.

Adler, G. (2010). Driving decision-making in older adults with dementia. Dementia, 9(1), 4560. DOI:10.1177/1471301209350289

Berger, P. L. and Luckmann, T. (1991). The social construction of reality: A treatise in the sociology of knowledge (No. 10). Penguin UK.

Berry, B., Apesoa-Varano, E. C. and Gomez, Y. (2015). How family members manage risk around functional decline: The autonomy management process in households facing dementia. Social Science \& Medicine, 130, 107-114.

Boyle, G. (2013a). 'She's usually quicker than the calculator': financial management and decision-making in couples living with dementia. Health and Social Care in the Community, 21(5), 554-562. DOI: 10.1111/hsc.12044

Boyle, G. (2013b). Facilitating decision-making by people with dementia: is spousal support gendered? Journal of Social Welfare and Family Law, 35(2), 227-243.

Boyle, G. (2014a). Recognising the agency of people with dementia. Disability \& Society, 29(7), 1130-1144.

Boyle, G. (2014b). 'Can't cook, won't cook': men's involvement in cooking when their wives develop dementia. Journal of Gender Studies, 23(4), 336-350.

Brand-Gruwel, S., Wopereis, I. and Walraven, A. (2009). A descriptive model of information problem solving while using internet. Computers \& Education, 53(4), 1207-1217. 
Cohen, J. (1960). A coefficient of agreement for nominal scales. Educational and Psychological Measurement, 20, 37-46. doi: 10.1177/001316446002000104

Couture, M., Ducharme, F. and Lamontagne, J. (2012). The role of health care professionals in the decision-making process of family caregivers regarding placement of a cognitively impaired elderly relative. Home Health Care Management \& Practice, 24(6), 283291. doi: $10.1177 / 1084822312442675$

Dening, K. H., King, M., Jones, L. and Sampson, E. L. (2017). Healthcare decisionmaking: Past present and future, in light of a diagnosis of dementia. International journal of palliative nursing, 23(1), 4-11.

Department of Health. (2005). Mental Capacity Act 2005: Code of Practice. London: The Stationery Office.

Dickinson, C., Bamford, C., Exley, C., Emmett, C., Hughes, J. and Robinson, L. (2013). Planning for tomorrow whilst living for today: the views of people with dementia and their families on advance care planning. International Psychogeriatrics, 25(12), 2011-2021.

Fetherstonhaugh, D., McAuliffe, L., Bauer, M. and Shanley, C. (2016). Decision-making on behalf of people living with dementia: how do surrogates decision-makers decide? Journal of medical ethics, medethics-2015.

Fetherstonhaugh, D., Tarzia, L. and Nay, R. (2013). Being central to decision-making means I am still here! the essence of decision-making for people with dementia. Journal of Aging Studies, 27(2), 143-150. doi: 10.1016/j.jaging.2012.12.007

Giddens, A. (1986). The constitution of society: Outline of the theory of structuration (Vol. 349). Univ of California Press.

Gilleard, C. and Higgs, P. (2010). Aging without agency: Theorizing the fourth age. Aging \& Mental Health, 14(2), 121-128. 
Higgs, P. and Gilleard, C. (2015). Rethinking old age: Theorising the fourth age. Palgrave Macmillan.

Gimpel, H. (2008). Cognitive Biases in Negotiation Processes. In Negotiation, Auctions, and Market Engineering (pp. 213-226). Berlin, Heidelberg: Springer.

Groen-van de Ven, L., et al. (2017). Decision trajectories in dementia care networks: decisions and related key events. Research on aging, 39(9), 1039-1071.

Hegde, S. and Ellajosyula, R. (2016). Capacity issues and decision-making in dementia. Annals of Indian Academy of Neurology, 19(Suppl 1), S34.

Hirschman, K. B., Xie, S. X., Feudtner, C. and Karlawish, J. H. (2004). How does an Alzheimer's disease patient's role in medical decision making change over time?.Journal of geriatric psychiatry and neurology, 17(2), 55-60.

Juárez-Cedillo, T., Jarillo-Soto, E. C. and Rosas-Carrasco, O. (2014). Social Representation of Dementia and Its Influence on the Search for Early Care by Family Member Caregivers. American Journal of Alzheimer's Disease \& Other Dementias ${ }^{\circledR}, 29(4)$, 344-353.

Kristensen, H. and Gärlinga, T. (1997). Adoption of cognitive reference points in negotiations. Acta Psychologica, 97(3), 277-288.

Landis, J. R. and Koch, G. G. (1977). The measurement of observer agreement for categorical data. Biometrics, 33, 159-74.

Livingston, G., et al. (2010). Making decisions for people with dementia who lack capacity: qualitative study of family carers in UK. BMJ, 341, c4184.

Lonergan, B. (2000). Insight: A study of human understanding. Canada: University of Toronto Press. 
Marson, D. C., Ingram, K. K., Cody, H. A. and Harrell, L. E. (1995). Assessing the competency of patients with Alzheimer's disease under different legal standards: A prototype instrument. Archives of neurology, 52(10), 949-954.

MacQuarrie, C. R. (2005). Experiences in early stage Alzheimer's disease: Understanding the paradox of acceptance and denial. Aging \& Mental Health, 9(5), 430-441. doi: $10.1080 / 13607860500142853$

Moher, D., Liberati, A., Tetzlaff, J. and Altman, D. G. (2009). Preferred Reporting Items for Systematic Reviews and Meta-Analyses: The PRISMA Statement. British Medical Journal, 339, b25-35.

Noblit, G. and Hare, R. (1988). Meta-ethnography: synthesising qualitative studies. Newbury Park, CA: Sage Publications.

NVivo. (2012). Qualitative data analysis Software. Melbourne, Australia: QSR International Pty Ltd.

Sackett, D., Richardson, W. S., Rosenburg, W. and Haynes, R. B. (1997). How to practice and teach evidence based medicine. London: Churchill Livingstone.

Sampson, M. S. and Clark, A. (2016). ‘Deferred or chickened out?’ Decision making among male carers of people with dementia. Dementia, 15(6), 1605-1621.

Samsi, K. and Manthorpe, J. (2013). Everyday decision-making in dementia: findings from a longitudinal interview study of people with dementia and family carers. International Psychogeriatrics, 25(6), 949-961. doi: 10.1017/S1041610213000306

Schütz, A. (1962). Collected papers 1. The Hague, Netherlands: Martinus Nijhoff. 
Smebye, K. L., Kirkevold, M. and Engedal, K. (2012). How do persons with dementia participate in decision-making related to health and daily care? A multi-case study. BMC Health Services Research, 12, 241. doi: 10.1186/1472-6963-12-241

St-Amant, O., et al. (2012). Making care decisions in home-based dementia care: Why context matters. Canadian Journal of Aging, 31(4), 423-434.

doi:10.1017/S0714980812000396

United Nations Convention on the Rights of Persons with Disabilities and Optional Protocol. (2006). Retrieved from http://www.un.org/disabilities/documents/convention/convoptprot$\underline{\text { e.pdf }}$

White, E. B. and Montgomery, P. (2014). Electronic tracking for people with dementia: an exploratory study of the ethical issues experienced by carers in making decisions about usage. Dementia, 13(2), 216-232. 
Appendix A1. Lonergan's (2000) hierarchical cognitive model of decision making.

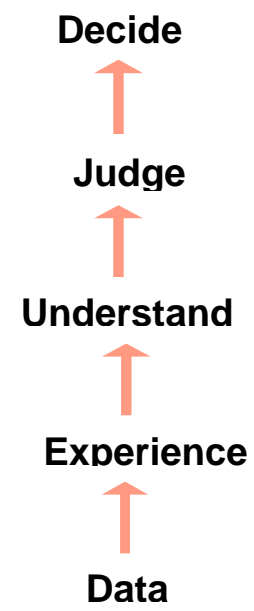

Figure 1. Flow chart for selection of papers.

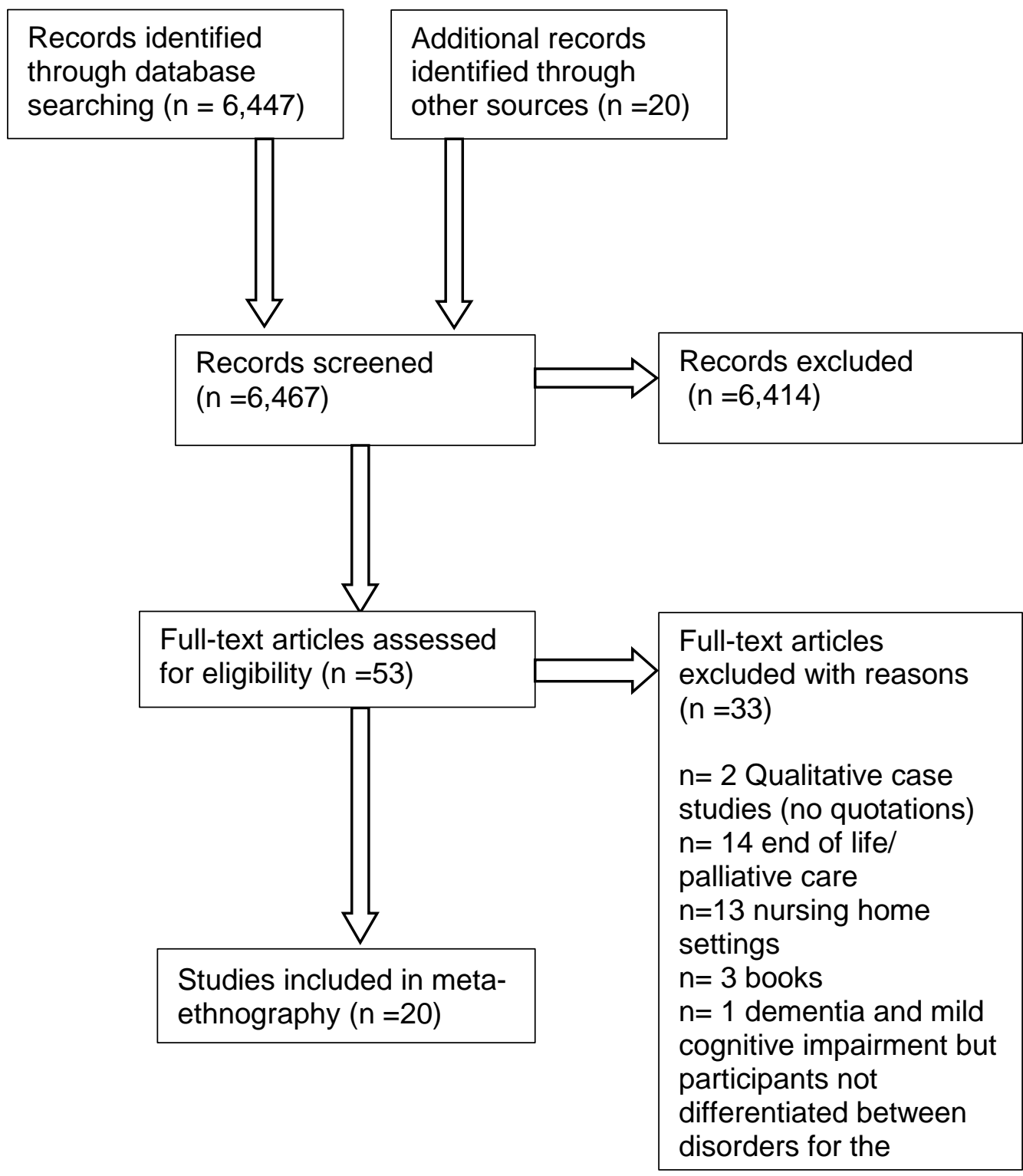


Table 1. Study characteristics $(n=20)$

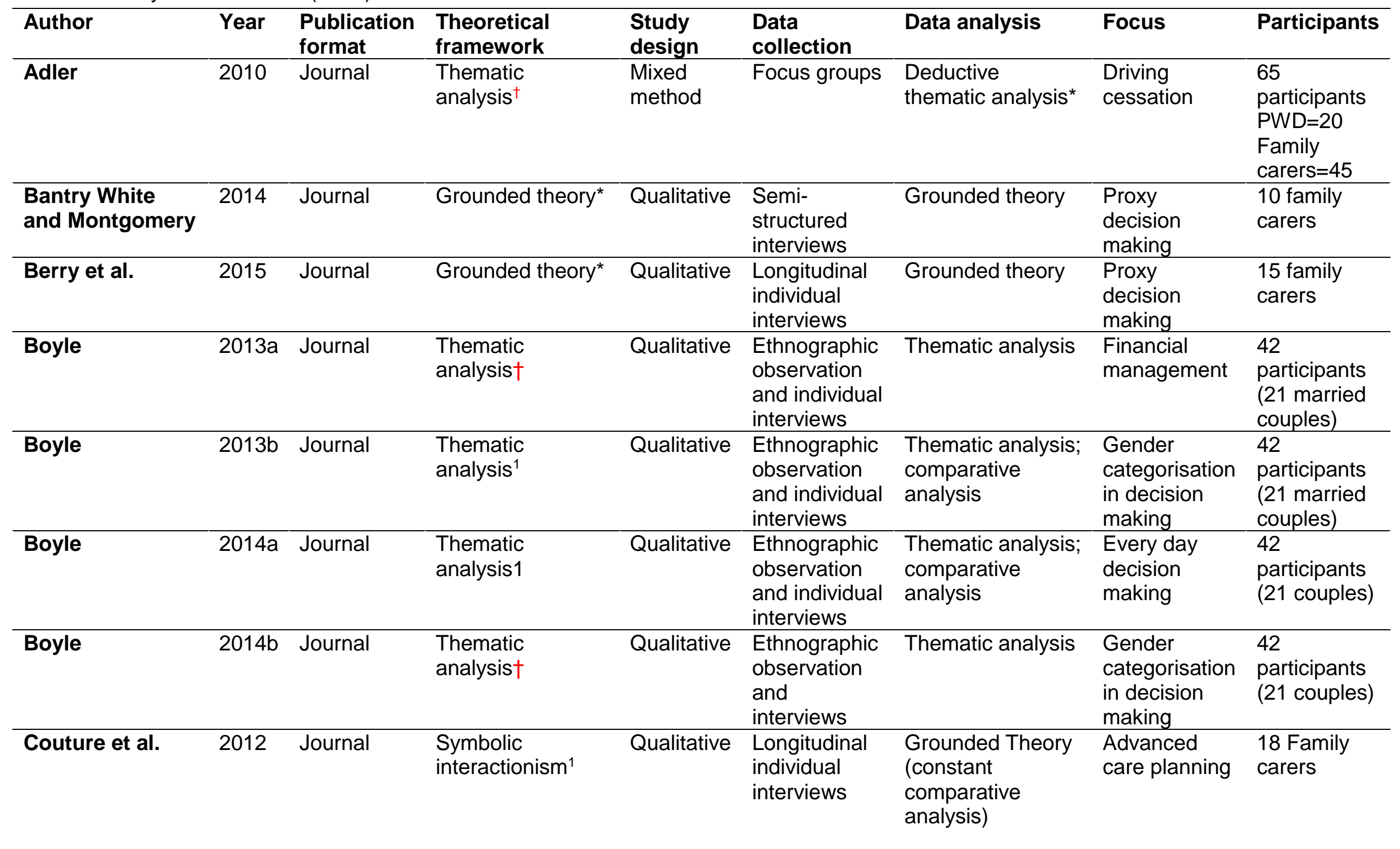




\begin{tabular}{|c|c|c|c|c|c|c|c|c|}
\hline Dickinson et al. & 2013 & Journal & $\begin{array}{l}\text { Thematic } \\
\text { analysis }^{1}\end{array}$ & Qualitative & $\begin{array}{l}\text { Semi- } \\
\text { structured } \\
\text { interviews } \\
\text { (dyadic and } \\
\text { individual } \\
\text { interviews) }\end{array}$ & Thematic analysis & $\begin{array}{l}\text { Advanced } \\
\text { care planning }\end{array}$ & $\begin{array}{l}46 \\
\text { Participants } \\
\text { PWD=17 } \\
\text { Family } \\
\text { carers=29 }\end{array}$ \\
\hline $\begin{array}{l}\text { Fetherstonhaugh } \\
\text { et al. }\end{array}$ & 2013 & Journal & Phenomenology $y^{1,2}$ & Qualitative & $\begin{array}{l}\text { Individual (in } \\
\text { person and } \\
\text { telephone) } \\
\text { interviews }\end{array}$ & $\begin{array}{l}\text { Phenomenological } \\
\text { analysis }\end{array}$ & $\begin{array}{l}\text { Every day } \\
\text { decision- } \\
\text { making }\end{array}$ & 6 PWD \\
\hline $\begin{array}{l}\text { Fetherstonhaugh } \\
\text { et al. }\end{array}$ & 2016 & Journal & $\begin{array}{l}\text { Thematic } \\
\text { analysis } \dagger\end{array}$ & Qualitative & $\begin{array}{l}\text { Semi- } \\
\text { structured } \\
\text { individual } \\
\text { interviews (in } \\
\text { person and } \\
\text { telephone) }\end{array}$ & Thematic analysis & $\begin{array}{l}\text { Proxy } \\
\text { decision } \\
\text { making }\end{array}$ & $\begin{array}{l}34 \text { Family } \\
\text { Carers }\end{array}$ \\
\hline $\begin{array}{l}\text { Groen-van de } \\
\text { Ven et al. }\end{array}$ & 2017 & Journal & Grounded theory ${ }^{3}$ & Qualitative & $\begin{array}{l}\text { Longitudinal } \\
\text { individual } \\
\text { interviews }\end{array}$ & $\begin{array}{l}\text { Constant } \\
\text { comparison } \\
\text { content analysis }\end{array}$ & $\begin{array}{l}\text { Every day } \\
\text { decision } \\
\text { making }\end{array}$ & $\begin{array}{l}113 \\
\text { Participants } \\
\text { PWD=23 } \\
\text { Family } \\
\text { carers=44 } \\
\text { Formal } \\
\text { carers=46 }\end{array}$ \\
\hline $\begin{array}{l}\text { Harrison Dening } \\
\text { et al. }\end{array}$ & 2016 & Journal & $\begin{array}{l}\text { Thematic } \\
\text { analysis* }\end{array}$ & $\begin{array}{l}\text { Mixed } \\
\text { method }\end{array}$ & $\begin{array}{l}\text { Semi- } \\
\text { structured } \\
\text { interviews }\end{array}$ & Thematic analysis & $\begin{array}{l}\text { Advanced } \\
\text { care planning }\end{array}$ & $\begin{array}{l}13 \\
\text { participants } \\
\text { PWD=6 } \\
\text { Family } \\
\text { carers }=7\end{array}$ \\
\hline $\begin{array}{l}\text { Juárez-Cedillo et } \\
\text { al. }\end{array}$ & 2013 & Journal & Content analysis* & Qualitative & $\begin{array}{l}\text { Individual } \\
\text { interviews }\end{array}$ & $\begin{array}{l}\text { Content analysis* } \\
\text { (statement } \\
\text { semiotics) }\end{array}$ & $\begin{array}{l}\text { Proxy } \\
\text { decision } \\
\text { making }\end{array}$ & $\begin{array}{l}8 \text { family } \\
\text { carers }\end{array}$ \\
\hline Livingston et al. & 2010 & Journal & Content analysis $†$ & Qualitative & $\begin{array}{l}\text { Focus group } \\
\text { and in-depth } \\
\text { individual } \\
\text { interviews }\end{array}$ & Content analysis & $\begin{array}{l}\text { Every day } \\
\text { decision } \\
\text { making }\end{array}$ & $\begin{array}{l}89 \text { Family } \\
\text { carers }\end{array}$ \\
\hline
\end{tabular}




\begin{tabular}{|c|c|c|c|c|c|c|c|c|}
\hline Macquarrie & 2005 & Journal & Grounded theory $^{3}$ & $\begin{array}{l}\text { Mixed } \\
\text { method }\end{array}$ & $\begin{array}{l}\text { Individual } \\
\text { interviews }\end{array}$ & $\begin{array}{l}\text { Constant } \\
\text { comparative } \\
\text { analysis }\end{array}$ & $\begin{array}{l}\text { Every day } \\
\text { decision } \\
\text { making }\end{array}$ & 13 PWD \\
\hline $\begin{array}{l}\text { Sampson \& } \\
\text { Clark }\end{array}$ & 2016 & Journal & $\begin{array}{l}\text { Thematic } \\
\text { analysis }+\end{array}$ & Qualitative & $\begin{array}{l}\text { Individual } \\
\text { interviews }\end{array}$ & Thematic analysis & $\begin{array}{l}\text { Every day } \\
\text { decision } \\
\text { making }\end{array}$ & $\begin{array}{l}9 \text { family } \\
\text { carers }\end{array}$ \\
\hline $\begin{array}{l}\text { Samsi and } \\
\text { Manthorpe }\end{array}$ & 2013 & Journal & $\begin{array}{l}\text { Thematic } \\
\text { analysis }\end{array}$ & Qualitative & $\begin{array}{l}\text { Longitudinal } \\
\text { dyadic } \\
\text { interviews }\end{array}$ & Thematic analysis & $\begin{array}{l}\text { Every day } \\
\text { decision } \\
\text { making }\end{array}$ & $\begin{array}{l}30 \\
\text { participants } \\
\text { PWD }=15 \\
\text { Family } \\
\text { Carers }=15\end{array}$ \\
\hline Smebye et al. & 2012 & Journal & $\begin{array}{l}\text { Hermeneutic } \\
\text { interpretivism }^{1}\end{array}$ & $\begin{array}{l}\text { Mixed } \\
\text { method }\end{array}$ & $\begin{array}{l}\text { Semi- } \\
\text { structured } \\
\text { interviews } \\
\text { and } \\
\text { participant } \\
\text { observation }\end{array}$ & $\begin{array}{l}\text { Hermeneutic } \\
\text { Interpretive } \\
\text { analysis } \\
\text { Thompson's } \\
\text { taxonomy of } \\
\text { participation } \\
\text { levels. }\end{array}$ & $\begin{array}{l}\text { Every day } \\
\text { decision } \\
\text { making }\end{array}$ & $\begin{array}{l}30 \\
\text { participants } \\
P W D=10 \\
\text { Family } \\
\text { carer }=10 \\
\text { Formal } \\
\text { carer }=10\end{array}$ \\
\hline
\end{tabular}

${ }^{*}$ Not reported in detail by the author(s).

Paradigm: ${ }^{1}$ Constructivist/Interpretive; ${ }^{2}$ Descriptive/eidetic; ${ }^{3}$ Positivism; ${ }^{4}$ Pragmatism; Not reported ${ }^{5}$ (Definition of paradigm informed by Mayan, 2016). †Thematic analysis/Content analysis is used as both theoretical framework and analytical method. 
Table 2. Meta-ethnography: Third order constructs.

\begin{tabular}{|c|c|}
\hline Third order & Theme Categories \\
\hline \multirow{7}{*}{$\begin{array}{l}\text { Autonomous } \\
\text { decision-making } \\
\text { pathway }\end{array}$} & Preserved cognitive ability \\
\hline & - Acknowledgment of cognitive ability (Smebye et al., 2012; Boyle, 2013a; Fetherstonhaugh et al., 2013). \\
\hline & Strategies to promote autonomous decisions \\
\hline & - $\quad$ Aids (Adler, 2010; Fetherstonhaugh et al., 2013; Livingston et al., 2010). \\
\hline & - Exploring choices (Smebye et al., 2012; Boyle, 2013b; Boyle, 2014a; Fetherstonhaugh et al., 2016; \\
\hline & $\begin{array}{l}\text { Groen van de Ven, 2017; Dickinson et al., 2013; Berry et al., 2015). } \\
\text { - } \quad \text { Assertion of autonomy (White, and Montgomery, 2014; Berry et al., 2015; Macquarrie, 2005) }\end{array}$ \\
\hline & Restricted autonomy by the carer (Bantry et al., 2014; Berry et al., 2015) \\
\hline \multirow{12}{*}{$\begin{array}{l}\text { Shared decision- } \\
\text { making pathway }\end{array}$} & Shared responsibility \\
\hline & - Consensus decision (Groen-van de Ven, 2017; Harrison Dening et al., 2016; Samsi and Manthorpe, 2013) \\
\hline & Strategies for shared decision making \\
\hline & $\begin{array}{l}\text { - Assisted autonomy (Bantry White and Montgomery, 2014; Smebye et al., 2012; Boyle, 2013b; Boyle, 2014b; } \\
\text { Samsi and Manthorpe, 2013). }\end{array}$ \\
\hline & - Connecting present and future negotiations (Smebye et al., 2012). \\
\hline & - Consultation with professionals (Adler, 2010; Livingston et al., 2010). \\
\hline & Barriers to shared decision making \\
\hline & - Imposing views on the person. (Boyle, 2013b; Harrison Dening et al., 2016). \\
\hline & - Feeling objectified. (Macquarrie, 2005; Sampson and Clark, 2016) \\
\hline & - Perception of ability for decision making. (Smebye et al., 2012; Boyle, 2013b). \\
\hline & Missed opportunity for autonomous decision \\
\hline & $\begin{array}{l}\text { - Not given opportunity (Smebye et al., 2012; Boyle, 2013b; Boyle, 2014b; Fetherstonhaugh et al., 2013; } \\
\text { Fetherstonhaugh et al., 2016; St-Amant et al., 2012; Sampson and Clark, 2016). } \\
\text { - } \quad \text { Justified by the condition (Smebye et al., 2012; Boyle, 2014b; Couture et al., 2012; } \\
\text { Harrison Dening et al., 2016; Livingston et al., 2010; Samsi and Manthorpe, 2013; } \\
\text { Juárez-Cedillo et al., 2013). }\end{array}$ \\
\hline
\end{tabular}




\section{Pseudo-}

autonomous

decision-making

pathway

\section{Protective Factors}

- Sense of reciprocity (Juárez-Cedillo et al., 2013; Smebye et al., 2012; Boyle, 2013b;

Samsi and Manthorpe, 2013; Sampson and Clark, 2016).

- External support (Smebye et al., 2012; Couture et al., 2012; Livingston et al., 2010;

\section{Maintaining factors}

Samsi and Manthorpe, 2013).

- Inadequate dialogue (Fetherstonhaugh et al., 2013; Fetherstonhaugh et al., 2016;

Harrison Dening et al., 2016).

- False perception of doing the interest of the person (Smebye et al., 2012; Harrison Dening et al., 2016;

Sampson and Clark, 2016). 
Figure 2. Conceptual map of decision-making pathways in dementia care.

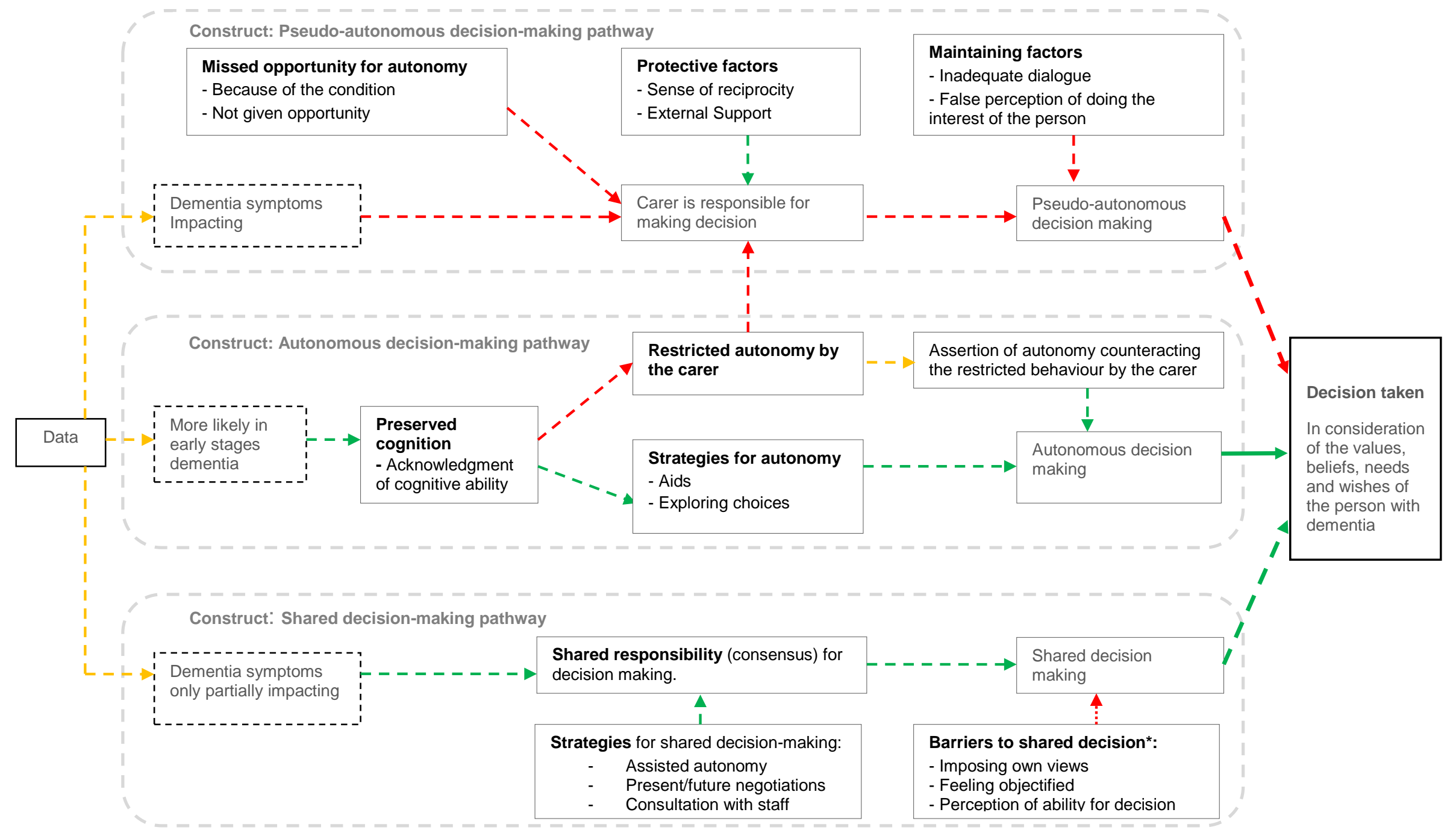

Each pathway is time-bound and influenced by the cognitive decline and dementia symptoms (be it physical or behavioural). In addition, autonomous decisions are a function of the quality of the care environment (e.g. nurturing care), and of metacognitive processes of self-awareness, self-reflection and self-monitoring in regard to the situation.

*Negative responses from the environment can lead to decreased autonomy and potentially to pseudo autonomous decision making. 
Figure 3. Metacognitive model of self-regulation in decision making (informed by Jones, 1997).

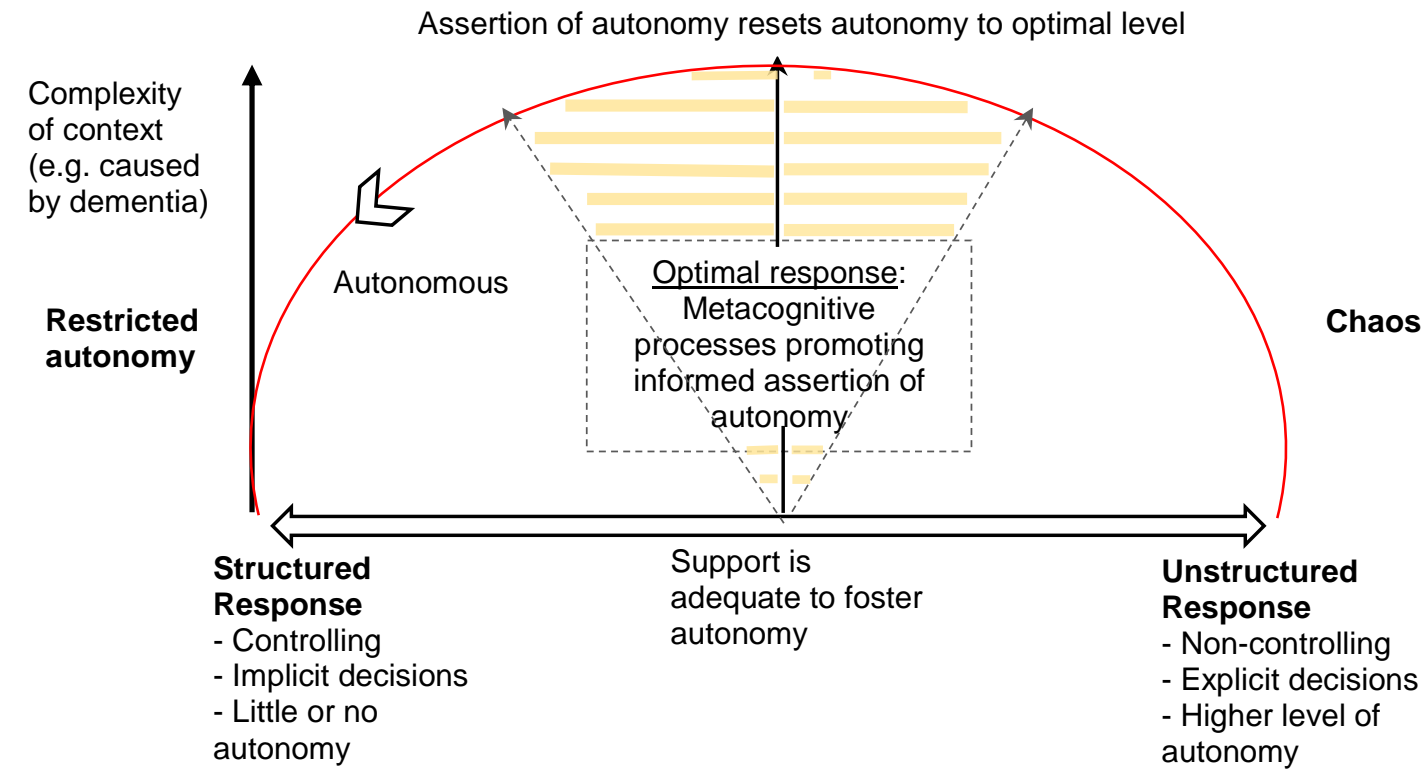

